\title{
VERS LE CENTENAIRE DE LA CROIX-ROUGE
}

Nous voici entrés dans cette année si importante, celle où, fraternellement unies, les Sociétés de la Croix-Rouge, du Croissant-Rouge et du Lion-et-Soleil-Rouge vont fêter, avec leurs institutions internationales, le Centenaire de notre mouvement. Et le premier anniversaire sera célébré le I7 février, date de la fondation, il y a un siècle, du Comité international.

Se retournant vers le passé et regardant la 'longue 'route jalonnée de tant d'cuvres utiles, de tant d'efforts toujours plus larges et audacieux, tous ceux qui collaborent de près ou de loin à la Croix-Rouge eprouveront un sentiment de fierté. Mais, aussi, songeant que ces ceuvres et ces efforts sont suscités, comme commandés, par un monde divisé et où les moyens de destruction sont devenus terrifiants, ils seront peut-être pris de doute. Le bien grandit-il en fonction même du mal qui grandit?

Non, cette année du Centenaire doit être, pour nous en particulier, une leçon de confiance, un acte d'espérance. C'est ce que disent $M$. Siordet, dans l'article que nous sommes heureux de publier ciaprès, et $M$. Logoz, qui nous indiquera ce qui se prépare actuellement à Genève.

Nos lecteurs auront constaté aussi que la couverture de la Revue internationale a changé d'aspect. Durant l'année 1963 , elle portera l'emblème du Centenaire et rappellera ainsi à chacun, mois après mois, l'importance de l'événement et la signification profonde qui s'y attache. (Réd.)

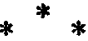

